\author{
Artur Simões Rozestraten \\ Lizete Maria Rubano \\ Lourenço Gimenes \\ Marcelo Rosenbaum \\ Marco Aurélio Oliveira
}

Nova SEDE ONG LUA NOVA:

UMA EXPERIÊNCIA COLETIVA DE PROJETO

ARQUITETURA, PROJETOS SOCIAIS,

INCLUSÃO, INTERVENÇÃO, ESTUDO DE

CASO, PARTICIPAÇÃO

\section{INTRODUÇÃ O}

O texto que aqui se apresenta foi escrito a várias mãos, como relato e reflexão sobre o processo de projeto para a nova sede da Ong Lua Nova em Votorantim, São Paulo, desenvolvido em julho de 2011. Considerando a dimensão existencial do projeto e a multiplicidade de agentes envolvidos nessa experiência, pode-se dizer que a autoria deste texto, das imagens que a ele se entrelaçam e do próprio projeto arquitetônico sobre o qual reflete, é coletiva, envolve vários arquitetos, professores, um grupo de 11 estudantes de arquitetura, além das jovens mães, crianças e coordenadores da Ong.

\section{Antecedentes}

É sobre um problema prático e objetivo que o presente trabalho se debruça. Devido a uma situação emergencial, determinada pelo injustificado despejo da Ong Lua Nova de suas instalações, organizou-se um esforço plural que tentou traduzir a importância do trabalho social dessa instituição.

A Associação Lua Nova - <http://www.luanova.org.br/> (Acesso em: 15 set. 2011) é uma organização não-governamental, sem fins lucrativos, sob a coordenação de Raquel Barros, que dá condições para que mulheres em situação de risco possam desenvolver uma relação saudável com a maternidade e, ao mesmo tempo, (re)inserir-se na sociedade e na própria família. São mulheres à margem de tudo, muitas vezes menores de idade, com histórico de dependência de drogas, abuso sexual e pobreza extrema. São mulheres que testam nossa compreensão da prostituição e da criminalidade, muitas vezes herdadas da própria família, ou vistas como uma estratégia natural de sobrevivência. Por outro lado, também são mulheres cujas histórias comoventes e seus esforços por mudanças alimentaram e inspiraram 0 trabalho desenvolvido a muitas mãos durante uma semana, em laboratório de projetos que envolveu dois escritórios e seis instituições de ensino. 

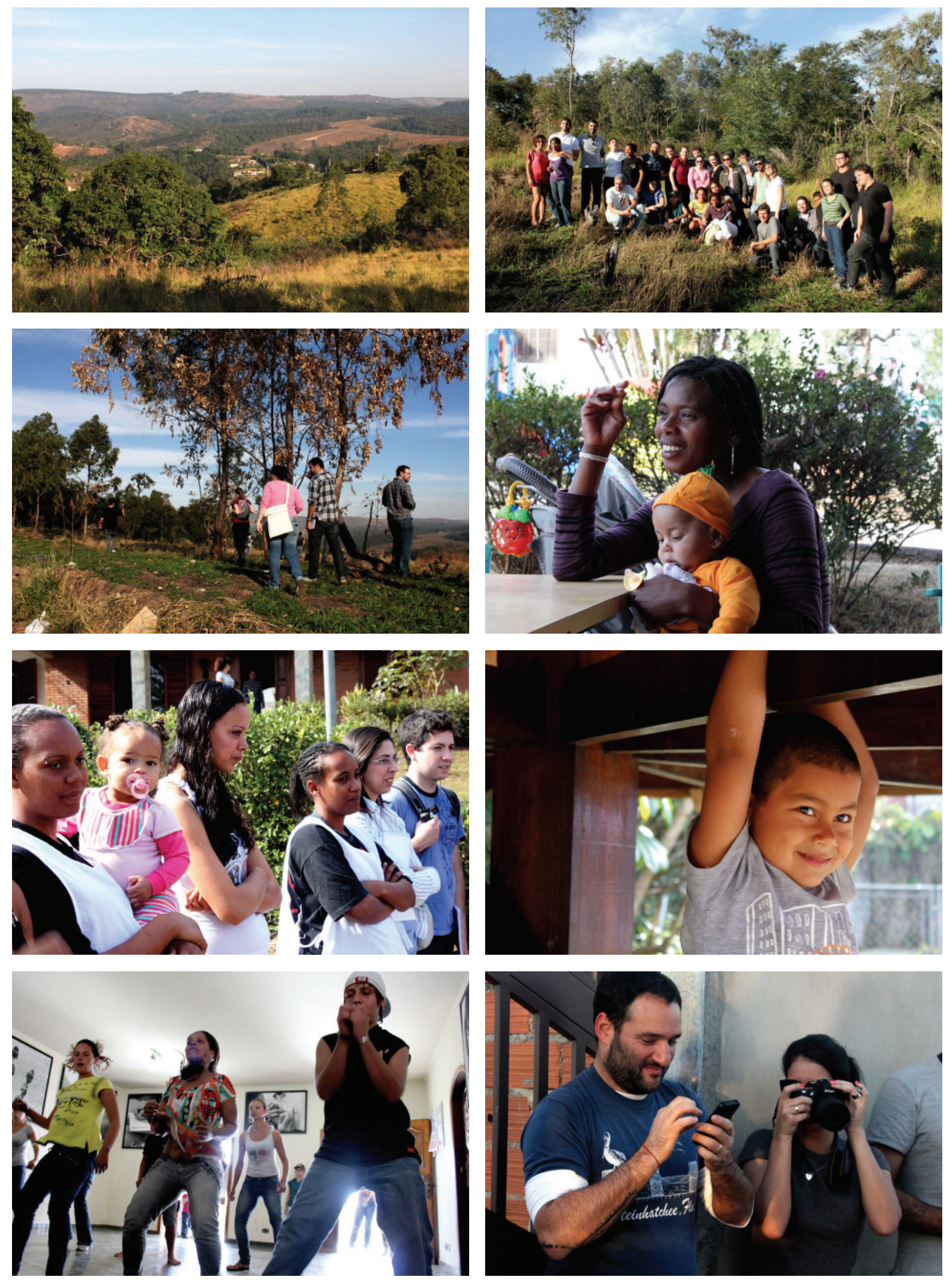
Dois escritórios, Rosenbaum e Forte, Gimenes \& Marcondes Ferraz Arquitetos (FGMF), foram inicialmente contatados por coordenadores da Lua Nova para auxiliarem no desenvolvimento de um projeto. Em instalações provisórias, a Ong contava com a promessa de concessão de um terreno pela prefeitura em Votorantim, cidade do interior paulista, mas, para tanto, precisava de um projeto para captar recursos para uma nova sede. Dos escritórios, partiu a ideia de organizar um trabalho coletivo, no qual a autoria do projeto fosse dividida com alunos quintanistas. Dessa forma, além de um resultado melhor (pressupondo que muitas cabeças pensam melhor que poucas), a intenção seria transformar esse projeto em oportunidade profissional efetiva para os alunos. Prestes a formar-se, o aluno poderia ganhar experiência com essa vivência, além de incrementar seus portfólios para buscar um trabalho ou, mesmo, aproveitar a oportunidade para montar um escritório com os novos colegas. Nasceu, assim, a ideia de "incubadora" de projetos, que é um dos aspectos dessa iniciativa.

\section{FORMATO E METODOLOGIA}

Não se pode deixar de mencionar, aqui, a experiência modeladora, ou pretensamente indicada para isso, na relação sociedade e intervenção no espaço. Nesse contexto, cabe ressaltar a valorização das questões sociais como objeto de integração dos esforços dos participantes. Tal processo, implementado metodologicamente, tem uma contribuição muito significativa, pois enfrenta as diferenças e reconhece, nas desigualdades sociais, mais que um desafio, questões a demandar a atuação responsável do arquiteto-urbanista.

A tangibilidade da questão, considerando a disponibilidade de terreno, a previsão real de construção e a objetividade da demanda, com "clientes reais", fez desse laboratório ou experiência, um exercício a demandar registro e análise.

É preciso dizer que, apesar das preocupações com a viabilidade técnica e econômica, prazo curto (uma semana), e programa real, foi possível incorporar, no formato do workshop, algum lirismo, se é que se pode definir desta forma: a intenção de um trabalho puramente horizontal, sem hierarquia baseada na experiência dos escritórios, permitiu um trabalho, de fato, coletivo, colaborativo e multifacetado.

Outro aspecto pertinente foi a junção de estudantes de seis faculdades, com perfis diferentes, o que garantiu a riqueza das discussões e a certeza que a pluralidade foi extremamente benéfica para o projeto. Entre elas, a Faculdade de Arquitetura e Urbanismo da Universidade de São Paulo (FAUUSP), o Mackenzie, a Belas Artes, a Fundação Armando Álvares Penteado (FAAP), a Escola da Cidade e a Universidade Paulista (Unip). A FAUUSP, além da contribuição voluntária dos alunos, generosamente disponibilizou o espaço do histórico casarão da FAUMaranhão para os encontros, provendo a equipe de toda a infraestrutura necessária pela receptividade e amabilidade do corpo docente e dos funcionários que acompanharam o processo.

A intensa "maratona" de uma semana de trabalho começou com uma viagem, no domingo 10 de julho de 2011, às instalações provisórias da Lua Nova e ao terreno alvo da intervenção. Lá, os participantes puderam conhecer de perto os problemas práticos, mas, sobretudo, conhecer as pessoas e suas histórias. 
Amparados pela metodologia de design thinking, pela participação de consultores cedidos por um patrocinador, no primeiro dia os participantes trataram de organizar as observações, questões, problemas, aspectos interessantes e soluções possíveis. Apesar de, como arquitetos, estarmos familiarizados com a necessidade de anamnese e sistematização do problema e do programa a ser enfrentado, a contribuição de uma metodologia complementar foi positiva. Normalmente, muito afeitos a artifícios gráficos, o enfrentamento da palavra, simbolizada pela avassaladora inundação de papéis adesivos nos primeiros dias do workshop, trouxe uma nova perspectiva e permitiu um alinhamento conceitual entre os participantes.

Outro alinhamento, de ordem mais subjetiva e emocional, foi conquistado com a generosa participação de Kaká Werá, responsável pelo Instituto Arapoti. Estudioso das tradições e da ancestralidade indígenas, o indianista promoveu dinâmicas de grupo com o propósito de "alinhar as vibrações" dos participantes. Em belíssima cerimônia de exercício vocal e corporal, os participantes compreenderam o sentido de coletividade característico das tribos indígenas. Puderam também entender 0 sentido da criatividade para os índios - uma vibração coletiva canalizada pelo homem, enfatizando o ato sempre coletivo de criação.

Durante a extenuante semana de trabalho, na qual todos participaram com dedicação exclusiva, dia e noite, houve outras contribuições valiosas. Professores do Mackenzie, FAAP, FAUUSP e Belas Artes puderam, pontualmente, expor seus pontos de vista e ressaltar questões importantes para o projeto. Além disso, foi fundamental a participação contínua de representantes da Lua Nova, que se revezaram em duplas ao longo da semana e ajudaram a testar as hipóteses e possibilidades projetuais. No meio da semana, uma apresentação inicial às meninas da Ong, que compareceram em peso, teve como objetivo validar as ideias e caminhos apontados. Muito participativas, em meio à grande euforia de entender-se como beneficiárias daquele processo, criticaram e contribuíram para a maturação do projeto - inclusive, servindo-se de papel e lápis para demonstrar seus comentários, como se imitassem a atividade projetual de forma tão ingênua quanto eficaz.

Após a consolidação do projeto, a reta final foi dedicada a desenvolver os desenhos e material para apresentação, que aconteceu na Sala dos Espelhos, no final da tarde de segunda-feira, 18 de julho, e foi aberta ao público em geral. Com a sala lotada, os participantes expuseram o resultado do trabalho.

\section{Projeto}

As palavras-chave que guiaram o projeto foram "generosidade" e "integração".

A generosidade se manifestou em uma implantação que tira partido do lote em declive, abrindo-se para uma paisagem exuberante, mas, sobretudo, está patente na relação com à comunidade do entorno. Na primeira sede que ocuparam, as meninas do Lua Nova chegaram a ter a casa cercada e apedrejada por vizinhos que consideravam o local um prostíbulo e ponto de drogas. Para combater uma nova manifestação de intolerância, o projeto partiu de uma premissa importante: parte do terreno seria cedido à comunidade, por meio de uma praça aberta. Essa praça estabelece a segunda premissa fundamental do projeto: integração. 

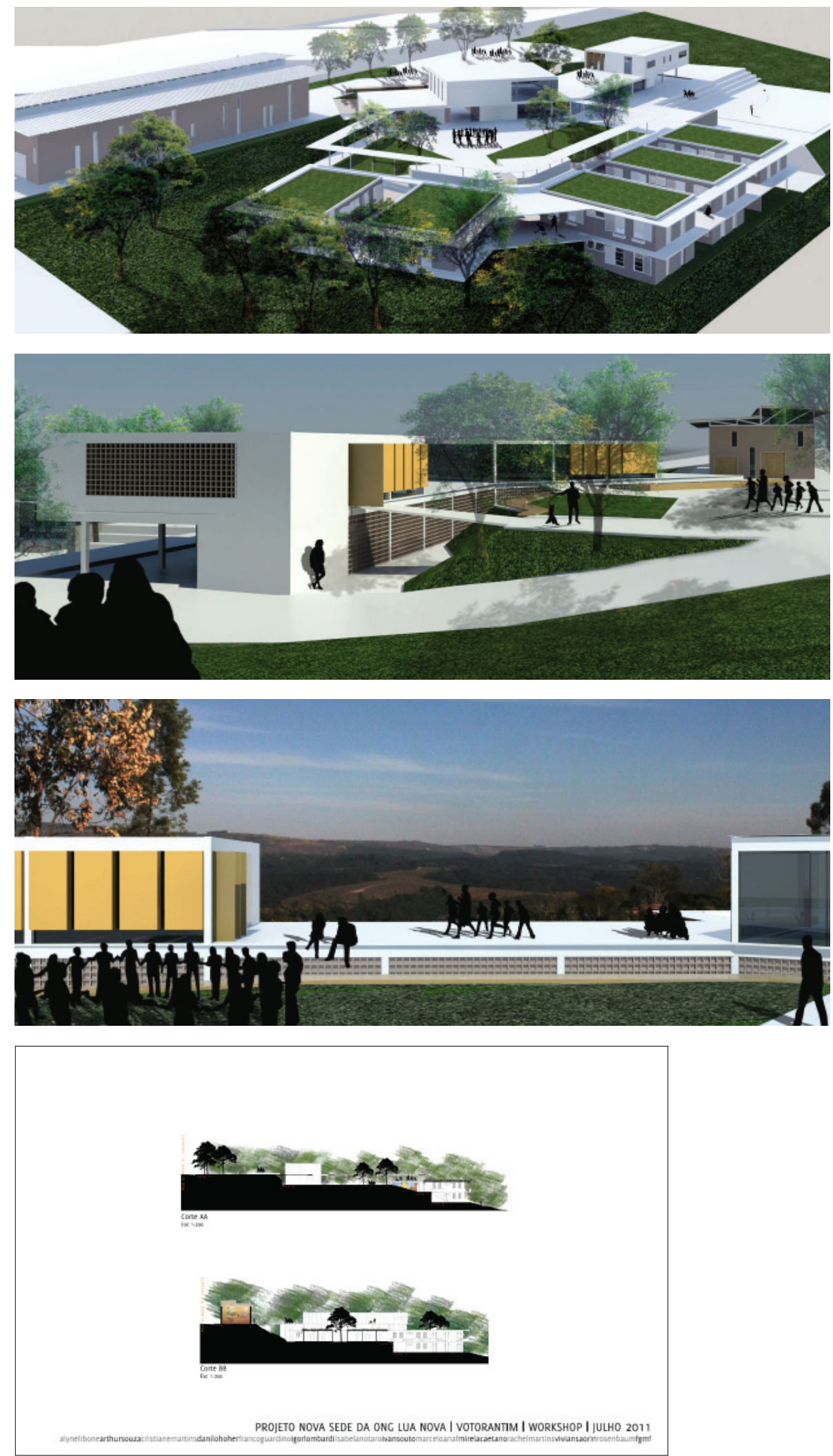

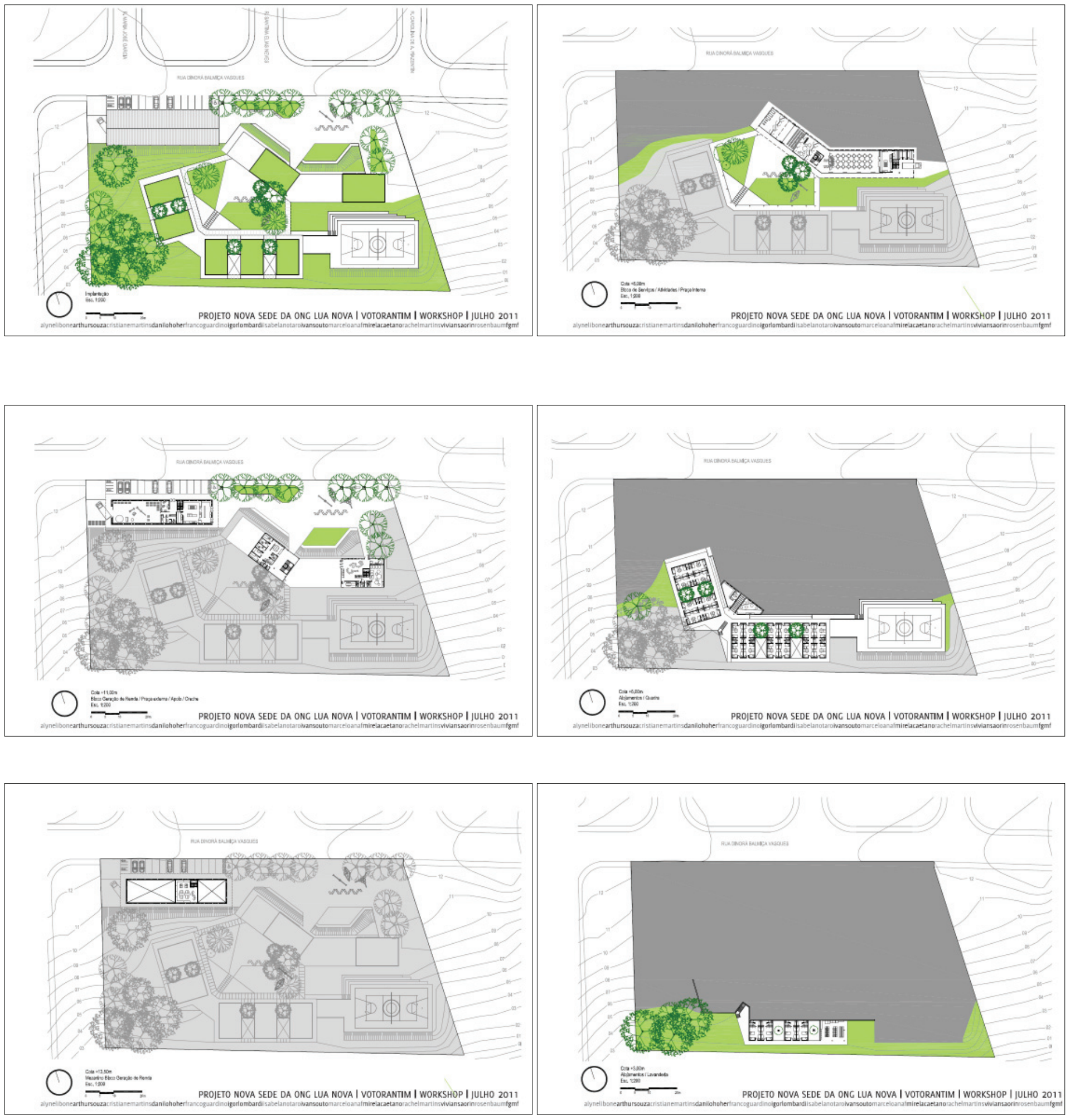


\section{REFLEXÕES CRÍTICAS}

As reflexões críticas, ou autocríticas, sobre o processo projetual para a nova sede da Ong Lua Nova que se pretende construir aqui, partem do reconhecimento de critérios, parâmetros e valores internos à relação entre os membros da Ong e a equipe de projeto.

Tal reconhecimento fundamenta a formulação de juízos analíticos e comparativos sobre estratégias, modi operandi, ou procedimentos metodológicos, elaborados e empregados para que o desenvolvimento do projeto contemplasse determinadas características na organização do problema (como proballó, sinônimo de projeto); na dinâmica do processo "formativo" (PAREYSON, 1993); e no projeto proposto (ARGAN, 1990).

Quanto à configuração do problema, ou das condições iniciais, provocativas e propulsoras das intenções e ações projetuais, cabe salientar aqui os seguintes critérios:

- O desenvolvimento de um estudo preliminar em uma semana de trabalho;

- a constituição de uma equipe de projeto composta por estudantes de diferentes faculdades, associados a arquitetos, para que a multiplicidade de olhares enriquecesse o processo e conduzisse a uma autoria coletiva;

- a aproximação direta à realidade física e humana da Lua Nova, por meio de visita, interações pessoais e registros in loco;

- a construção de conhecimento sobre o lugar (terreno/cidade/paisagem), a história da Ong e de suas instalações, assim como sobre as condições sociais, econômicas, culturais e tecnológicas nas quais se inseria a antiga sede, e aquela nas quais será inserida a nova;

- a constituição de uma dinâmica de trabalho coletivo que possibilitasse o diálogo entre todos os envolvidos (membros da Ong e equipe de projeto), o intercâmbio de experiências, a avaliação conjunta do processo e dos resultados (parciais e finais), e a emissão de opiniões sobre os conteúdos arquitetônicos;

- o desenvolvimento de um projeto enraizado nos anseios, necessidades e desejos das jovens mães da Lua Nova, no qual se conjugassem: funcionalidade, viabilidade construtiva, baixa manutenção, interação com o entorno imediato e a paisagem, e integração entre espaços internos e externos.

Quanto ao processo formativo ou à prática empregada para o desenvolvimento dos trabalhos, alguns aspectos dessa experiência merecem menção:

- O propósito experimental desse exercício de projeto coletivo que, do ponto de vista metodológico, sempre considerou a singularidade da experiência projetual como práxis possível, nunca como método, caminho seguro já conhecido, desvendado, passível de ser replicado;

- a partir de tais singularidades, desde o início considerou-se a necessidade de registrar o processo projetual em andamento, reconhecendo sua historicidade, a fragilidade de sua memória e sua contribuição à construção de conhecimento a respeito dos processos projetuais em arquitetura;

- a constituição de um "corpo coletivo" ou uma equipe de projeto ampliada (estudantes+arquitetos+membros da Lua Nova), capaz de valorizar as individualidades que a constituem, sem comprometer a coesão de grupo, indispensável para a realização do trabalho, no prazo necessário, e com os critérios mencionados; 
- o cronograma de trabalho muito curto que exigiu uma intensa preparação inicial, anterior à visita na área, assim como, necessariamente, desdobrar-se-á em etapas posteriores de desenvolvimento do projeto (anteprojeto, pré-executivo, executivo), com o apoio de outras equipes de projetistas, para que se encaminhe ao canteiro de obras;

- o reconhecimento a posteriori das seguintes etapas de trabalho: primeiro, o contato com o lugar, as pessoas envolvidas e as condicionantes de projeto; depois a constituição de modelos do lugar (fotografias, desenhos, anotações e maquetes), dos usuários (persona), e de seus anseios; em seguida, o desenvolvimento dos primeiros estudos; a apresentação dos mesmos para diálogo com todos os envolvidos; a revisão dos estudos a partir de tal interação; e, por fim, a apresentação da solução projetual;

- o papel ativo conferido às representações utilizadas como meios de elaboração do projeto, e não apenas como meios de expressão de ideias preconcebidas. Nesse processo, a palavra (falada e escrita) assumiu um papel principal, sintetizando conceitos, possibilitando a exposição de propósitos, dúvidas e inquietações, fundamentando, enfim, um campo de diálogo sobre arquitetura entre estudantes, arquitetos e leigos. Além da palavra, as representações gráficas (desenho e fotografia) e tridimensionais (modelos de estudo), também assumiram o mesmo sentido ativo, criativo, de interlocuções, embate e elaboração propositiva.

Quanto ao projeto, antes de tudo, diante da condição de desamparo da Lua Nova, retomou-se a proposição de Argan, em Projeto e destino (2000), de projetar-se:

contra a exploração do homem pelo homem; contra a mecanização da existência; contra a inércia do hábito e do costume; contra os tabus e as superstições; contra a agressão dos violentos; contra a adversidade das forças naturais; sobretudo projeta-se contra a resignação ao imprevisivel, ao acaso, à desordem, aos golpes cegos dos acontecimentos, ao destino [...].

Para tanto foi indispensável que houvesse condições de concentração para o trabalho, e que se cultivasse, entre todos os participantes, um ambiente colaborativo, solidário, de intercâmbio, complementaridade e convergência de esforços.

O projeto de arquitetura na realidade brasileira tem sido pouco utilizado como instrumento de transformação ou de construção da cidadania. Tal condição, posta ao projeto, foi apontada por Arantes, 1997, a partir da constituição mesma da arquitetura moderna brasileira: "(...) num país ainda mal acabado era flagrante... o descompasso entre a precária ou quase nula base material e as exigências da nova racionalidade construtiva." (ARANTES, 1997, p. 127)

Nesse sentido, ainda segundo Arantes, a inadequação entre "doutrina e pressuposto social" e o "viés estético enaltecido como marca nacional" acabaram por caracterizar, considerando nosso processo de formação uma arquitetura marcada pelo "jogo abstrato com as formas".

A busca pela condição primeira em que se elabora, desenvolve e apresenta a proposição moderna da arquitetura no Brasil, foi aqui resgatada, ainda que, pontualmente, na perspectiva de construir, criticamente, nossa percepção das possibilidades que o papel do projeto - arquitetônico e urbano - vem tendo na contemporaneidade. 
As experiências das políticas públicas que se utilizam dos recursos do projeto têm sido praticamente inexpressivas em nossa realidade urbana.

0 projeto tem sido muito mais instrumento de apropriação do capital privado, especulativo, que acentua a segregação e o diferencial nas cidades, do que recurso à construção da cidadania pela possibilidade de acesso a equipamentos de qualidade ou a situações de cidade democráticas e adequadas à vida.

Ainda, os processos de elaboração de projeto, se formos apontar outro tema significativo à discussão da experiência do workshop Lua Nova, têm sido valorizados essencialmente a partir do autor, da "marca pessoal" que um profissional pode imprimir a uma demanda dada objetivamente. É de consenso que, nesse caso, alguns desses autores pertencem ao star system e são, muitas vezes, solicitados quase como uma "grife" desejada que atribuiria valor diferenciado à mercadoria-edifício.

Poucos são os momentos em que se valoriza a produção coletiva, interdisciplinar, na qual as contribuições compõem de maneira diversa, de diferentes pontos de vista, uma alternativa a um problema dado.

É claro que esses dois temas, apontados anteriormente, são de caráter estrutural e uma experiência pontual não colocaria alguma alteração significativa nesses processos. Entretanto, é possível considerar que experiências representarem outra escala de valores ou desencadearem, realizando-se, de maneira outra, possibilidades de vivenciar-se de diferentes formas o processo de elaboração e de desenvolvimento de um projeto, possam, sim, ser exemplos de nova possibilidade de fazer-se, de construir-se alternativas às demandas reais.

Para Milton Santos (1994), "mesmo nos lugares onde os vetores da mundialização são mais operantes e eficazes, o território habitado cria novas sinergias e acaba por impor, ao mundo, uma revanche..." Considerando essa possibilidade, um trabalho como o da Ong Lua Nova e a integração de sua sede ao espaço da cidade, como um equipamento institucional importante que também atribui valor, pelo uso, ao lugar, pode representar uma pequena experiência em um outro sentido: o da elaboração coletiva, da responsabilidade pública com o tema, da inserção na cidade. Uma possibilidade de revanche, como haveria de ser.

O propósito crítico pretendido aqui, contudo, só pode se cumprir plenamente na medida em que - evidenciados os critérios condutores da ação projetiva - o leitor possa formular suas próprias opiniões sobre a tripla invenção do problema, do processo e do projeto, descritos aqui em texto e imagens para, assim, reinventá-los.

\section{REFERÊNCIAS}

ARGAN, Giulio Carlo. Projeto e destino. São Paulo: Ática, 2000.

PAREYSON, Luigi. Teoria da formatividade. Rio de Janeiro: Vozes, 1993.

SANTOS, Milton. O retorno do território. Território, globalização e fragmentação. São Paulo: Hucitec, 1994.

ARANTES, Otília. Lucio Costa e a "boa causa" da arquitetura moderna. In: ARANTES, Otília e; ARANTES, Paulo. Sentido da formação, três estudo sobre Antonio Candido, Gilda de Mello e Souza, e Lucio Costa. São Paulo: Paz e Terra, 1997. 

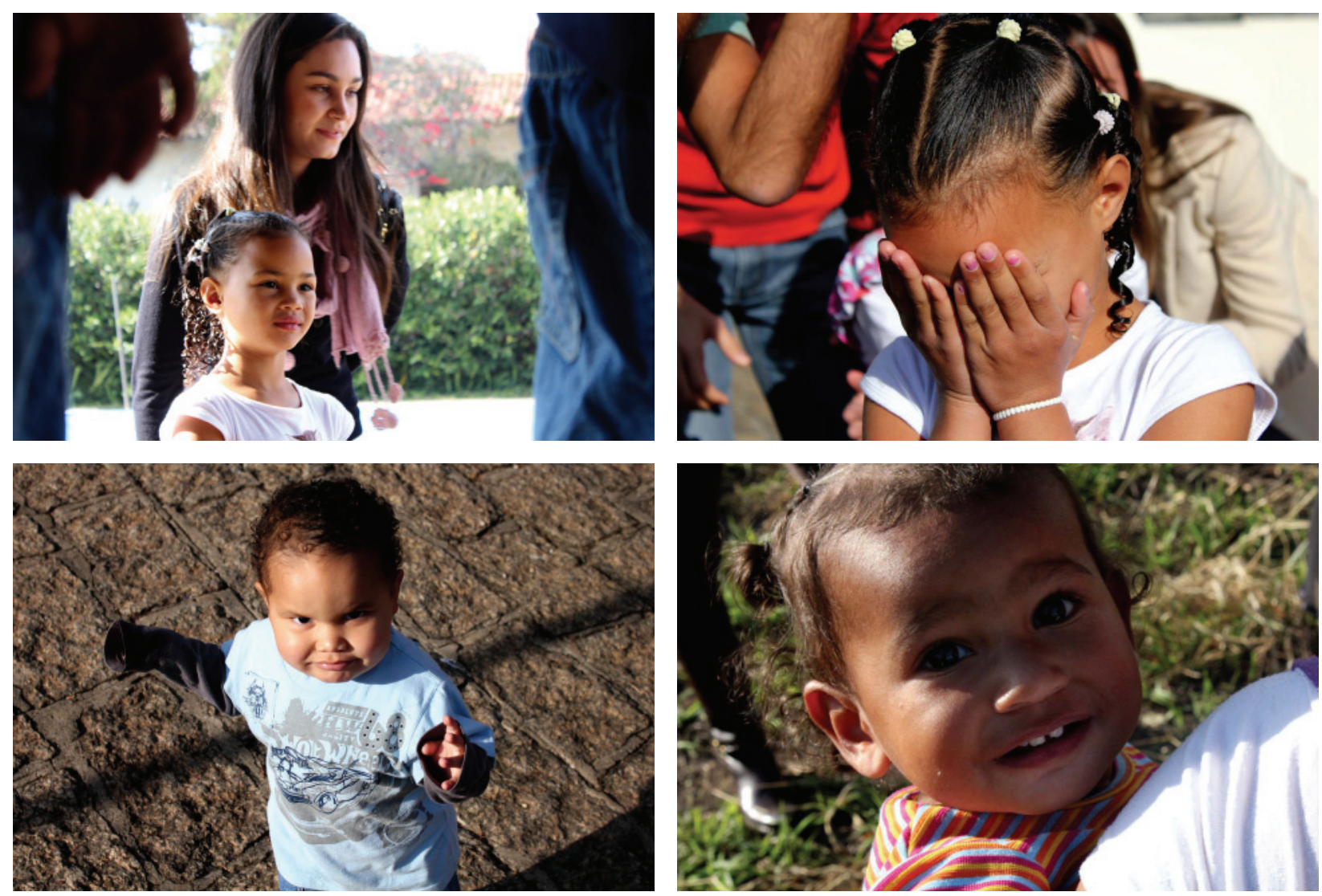

pós- $\mid \begin{aligned} & N \\ & \infty \\ & -1\end{aligned}$
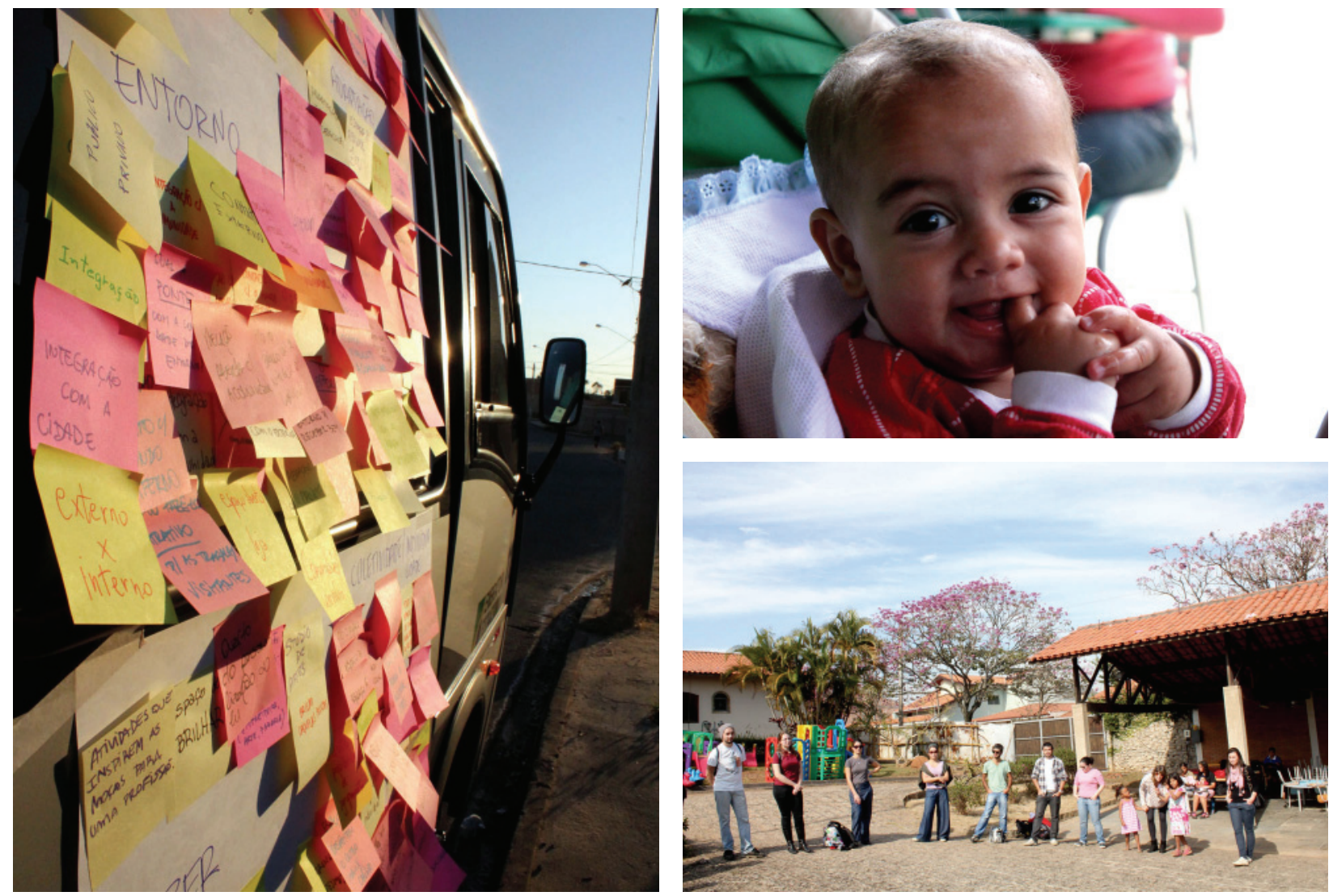


\section{EQUIPE:}

Alyne de Faria Liboni (Mackenzie), Arthur José Amaral de Souza Junior (USP), Cristiane Martins Dourados (Belas Artes), Danilo Hoher (Belas Artes), Franco Guardino (Mackenzie), Igor Lombardi Almeida (USP), Isabela Notaro (Belas Artes), Ivan Custódio dos Santos Souto (USP), Marcelo Anaf (FAAP), Mirela Cristina Faria Caetano (Escola da Cidade), Rachel Martins (Unip Sorocaba) e Vivian Saorin Ghiraldini (Belas Artes).

\section{Agradecimentos}

À Comissão de Pós-Graduação da FAUUSP, em especial à sua presidente, Profa. Dra. Maria Lucia Refinetti Rodrigues Martins, a todos os funcionários da FAUMaranhão, especialmente à Cristina Maria Arguejo Lafasse, e, para finalizar, à arquiteta Ana Paula Harumi Eguchi, pelo apoio indispensável ao longo de todo esse tempo.

\section{Artur Simões Rozestraten}

Professor doutor RDIDP junto do Departamento de Tecnologia da FAUUSP, na graduação e na pós-graduação.

artur.rozestraten@usp.br, aut@usp.br

\section{Lizete Maria Rubano}

Professora doutora, Projeto VIII (Arquitetura e Desenho Urbano), professora do curso de lato sensu: "O projeto de arquitetura na cidade contemporânea" - Módulo: Habitar a metrópole, com o professor arquiteto Héctor Vigliecca, Faculdade de Arquitetura e Urbanismo Mackenzie e coordenadora do grupo de pesquisa Vida Associada: Habitação e Cidade.

\section{Lourenço Gimenes}

Arquiteto e urbanista pela FAUUSP (2001), é mestre (2005) e cursou doutorado (2006-2009, incompleto) pela mesma instituição. Foi professor de Projeto na Unip e IED, além de assistente PAE na FAUUSP, professor-visitante no IMED e colaborador em programas do MIT e IHP. Como diretor do escritório de projetos FGMF, já recebeu mais de 40 prêmios nacionais e internacionais.

\section{Marcelo Rosenbaum}

Designer da Rosenbaum ${ }$, escritório de design e inovação, capaz de gerar valor a partir de ideias originais. A síntese do pensamento de trabalho da Rosenbaum ${ }^{\circledR}$ é o conceito do "morar" ampliado além do projeto do espaço físico e da estética do objeto.

\section{Marco Aurélio Oliveira}

Diretor de projetos e parcerias da NeoTropica - Instituto de Educação e Ciências Aplicadas, mestre e doutorando em Ciências pelo Departamento de Geografia da FFLCH-USP e professor do curso de Arquitetura e Urbanismo do Centro Universitário Belas Artes de São Paulo. 